\title{
The effect of a multimodality cardiac imaging elective on pre-clinical medical students
}

\author{
Rebecca Kusko MS, Marina Iskandir MD, Allen Haynes MD, Simon Williams MD, \\ Scott Shurmur MD, Mohammad M. Ansari MD
}

\begin{abstract}
The Texas Tech University Health Sciences Center School of Medicine has developed an immersive Cardiac Imaging and Innovation week for medical students during their preclinical year. A pre- and post-survey administered to participants showed increased knowledge and improved impressions of cardiology. The students ranked the experience as high quality. This project suggests that similar elective experiences could enhance education during the preclinical period of medical education.
\end{abstract}

Keywords: medical education, cardiology, technology, imaging, echocardiography

\section{INTRODUCTION}

Clinical experience while in medical school has an important impact on determining the specialty a student may choose to pursue. Enrichment experiences added to the traditional curriculum can provide insight into and interest in aspects of medicine and technology that students may not otherwise experience before applying to residency programs. Training as diverse as midwifery seminars, ${ }^{1}$ culinary medicine and nutrition, ${ }^{2}$ and additional training in varied specialties ${ }^{3}$ are offered during undergraduate medical education. In cases in which student feedback was conducted, the additions were shown to increase student insight into the relevant areas of medicine. ${ }^{2,3}$ Adding technology courses to medical education improves student learning, as reflected in the case of ultrasound and anatomy ${ }^{4}$ or in a preclinical elective experience focusing on technology in medicine. ${ }^{5}$

The School of Medicine at Texas Tech University Health Sciences Center (TTUHSC) in Lubbock, TX, has

Corresponding author: Mohammad M. Ansari

Contact Information: Mac.Ansari@ttuhsc.edu

DOI: 10.12746/swrccc.v8i35.721 developed a five-day Cardiac Imaging and Innovation Week to expose first- and second-year medical students to aspects of cardiology and medical technology that they may not have the chance to see during the traditional curriculum. This experience can drive interest in a specialty and provide a better ability to triage cardiac patients regardless of what field students ultimately choose. Students are given a preliminary look into available imaging cardiac modalities, such as transthoracic and transesophageal echocardiography, Doppler ultrasound, cardiac computed tomography (CT), cardiac magnetic resonance imaging (MRI), and nuclear medicine testing. They also had exposure to invasive procedures in the electrophysiology and interventional labs and exposure to innovative uses of 3D printing as applied to cardiology. Surveys of first- and second-year medical students who participated were conducted to assess perceptions of the field before and after the experience.

\section{Methods}

Cardiac Imaging and Innovation Week is a five-day mixture of lecture, clinical experiences, and workshops designed to introduce first- and second-year medical students to the use of technology in cardiology. It is held 
as part of an elective week dedicated to exploring subspecialties and aspects of medicine beyond the traditional curriculum. The Cardiac Imaging events are sponsored by the student run Technology in Medicine (TiM) elective (details of the elective in its entirety are discussed in Livingston et al.), whose members are strongly encouraged to attend all events. Attendance for each day was open to a limited number of outside students on a first come, first serve basis. All students in attendance and surveyed were firstor second-year medical students currently enrolled in the TTUHSC School of Medicine. The events for the week were as follows:

\begin{tabular}{|l|l|}
\hline Day 1 & $\begin{array}{l}\text { Introductory Session: 1 hour lecture } \\
\text { from cardiology fellow reviewing } \\
\text { cardiac anatomy and introducing } \\
\text { imaging techniques featured during the } \\
\text { following week. }\end{array}$ \\
\hline Day 2 & $\begin{array}{l}\text { Transesophageal Echocardiogram } \\
\text { (TEE) Simulator and CT and } \\
\text { MRI: 3 hours split into a faculty } \\
\text { demonstration and instruction on use } \\
\text { of TEE using a simulation model, and } \\
\text { faculty lecture overview of CT and } \\
\text { MRI followed by viewing of imaging } \\
\text { being done on the hospital floor. }\end{array}$ \\
\hline Days 3 and 4 & $\begin{array}{l}\text { Nuclear Modalities, Fluoroscopy and } \\
\text { Cath Lab, Electrophysiology Mapping, } \\
\text { and Echocardiogram: Each modality is } \\
\text { viewed in the hospital by students and } \\
\text { explained by faculty and hospital staff } \\
\text { for an hour each, with the four modalities } \\
\text { spread over two days which feature } \\
\text { viewing of interventional cardiology } \\
\text { procedures in an interactive setting. }\end{array}$ \\
$\begin{array}{l}\text { 3D Printing and Medical Uses: The } \\
\text { ability to download and manipulate } \\
\text { images into 3D modeling software } \\
\text { (SolidWorks) is shown; models of the } \\
\text { heart are sliced along the parasternal } \\
\text { axis and 3D printed. }\end{array}$ \\
\hline Day 5
\end{tabular}

To evaluate the week, pre-and post-surveys were sent out to TiM students via an email link to a Google
Form before the elective and then on the last day after the last session. Respondents ranked several measures on a Likert scale from 1 to 5 . In addition, on the post-survey, respondents were asked to indicate which events they attended and were given a space for free commentary. The full text of the pre- and post-survey is shown in Figure 1.

Analysis of this self-assessment was performed using Prism, version 8.3.0, a data analysis and display software package. A t-test was performed in Prism, which analyzed the data using the Holm-Sidak method with an alpha of 0.05 , not assuming a consistent standard deviation. Additional feedback for each individual event was available through TTUHSC's oversight of the week, in the form of an electronic survey mailed to all attendees, approximately 1 week after the completion of the elective. Days 1 and 5 events were gauged by a different question set than Day 2-4 events, which is reflected in Figure 2. Averages and numbers of respondents were given to the authors by the course coordinator.

\section{RESULTS}

The results of the pre and post survey administered by the authors are shown in Figure 2.

Mean, 95\% confidence intervals, and t-test results were calculated from the data using Prism. For all metrics the pre-test means ranged from 1.875 to 2.750 , while the post-test means ranged from 3.625 to 4.500 . The largest improvement was seen in "Knowledge of electrophysiology, nuclear medicine, ultrasound, and catheterization."

The number of student responses along with their overall experience ratings are tabulated in Figure 3. All sessions during P3 Week were categorized as either breakout sessions that took place in a classroom setting with lecture-based instruction and training (Days 1 and 5), or clinical sessions that featured hands on experience (Days 2-4). Different sets of questions were given for sessions categorized as breakout versus sessions categorized as clinical. All questions were scored on a Likert scale from 1 to 5 ; the results are shown in Figure 2. 


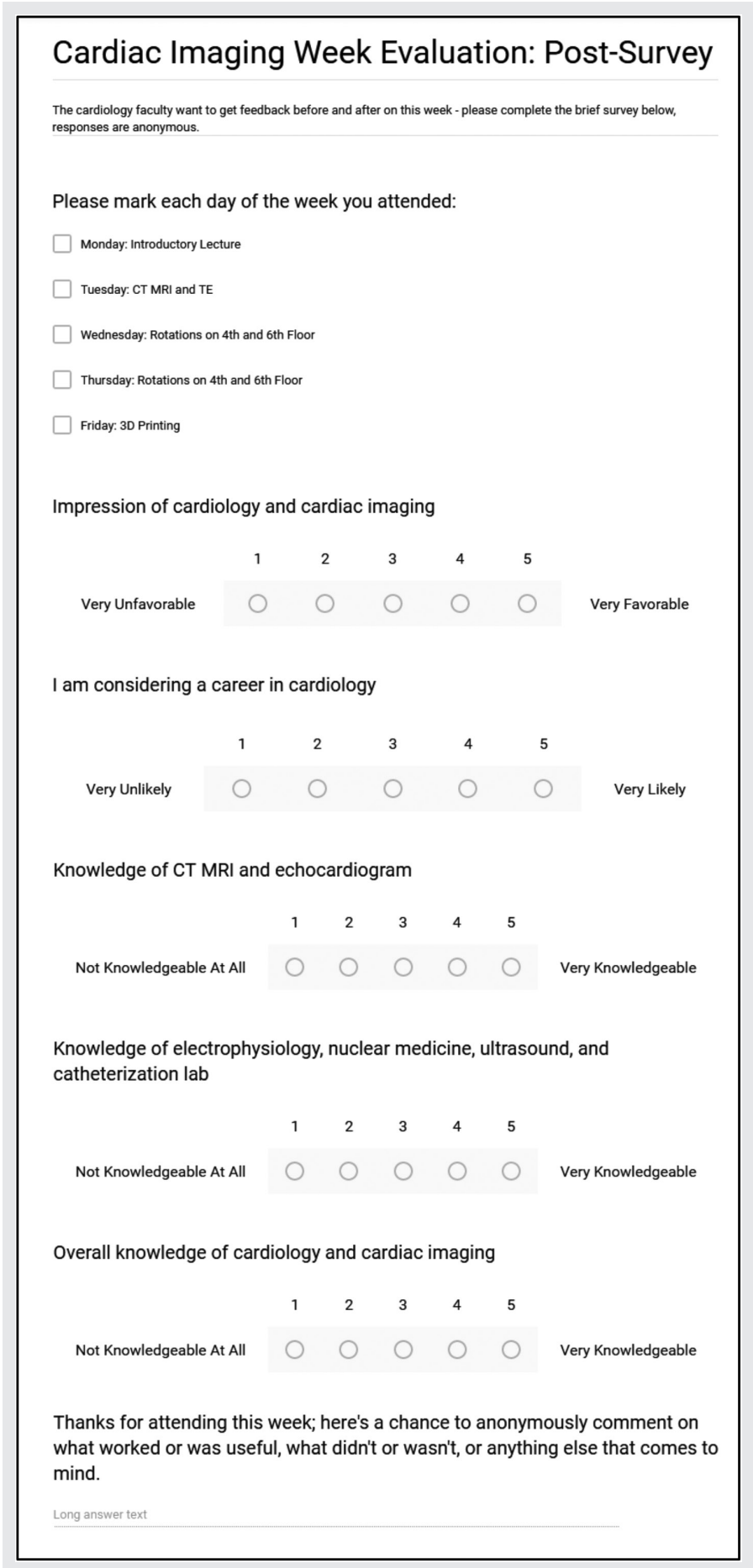

Figure 1. Survey given before and after the elective week.

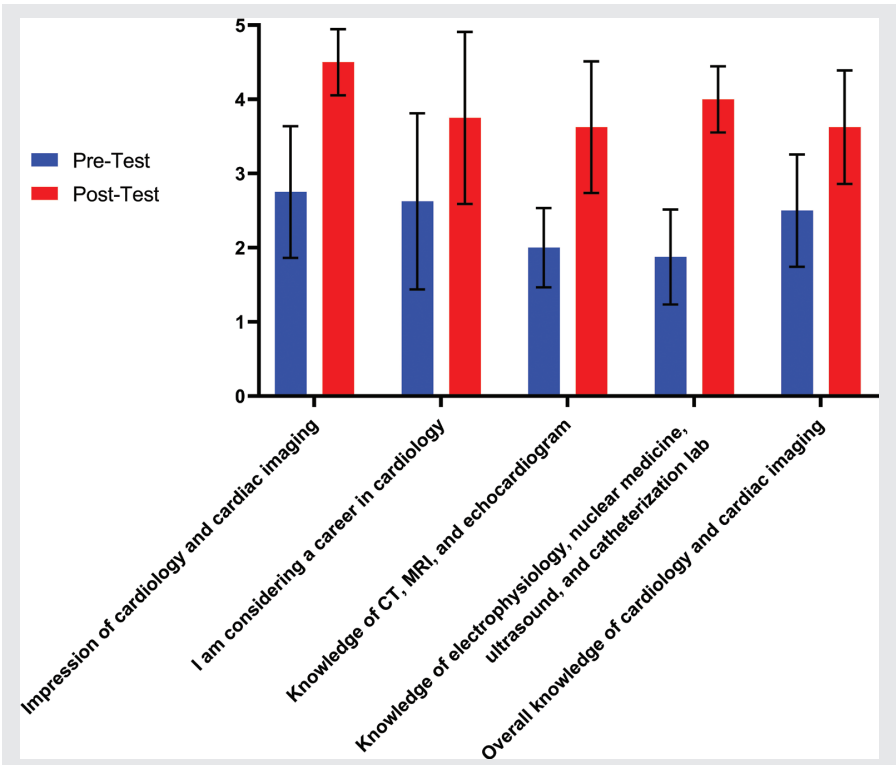

Figure 2. Responses of 8 Cardiac Week participants graded on a 1 to 5 Likert scale. The error bars on the graph represent $95 \%$ confidence interval as calculated by the Prism software package.

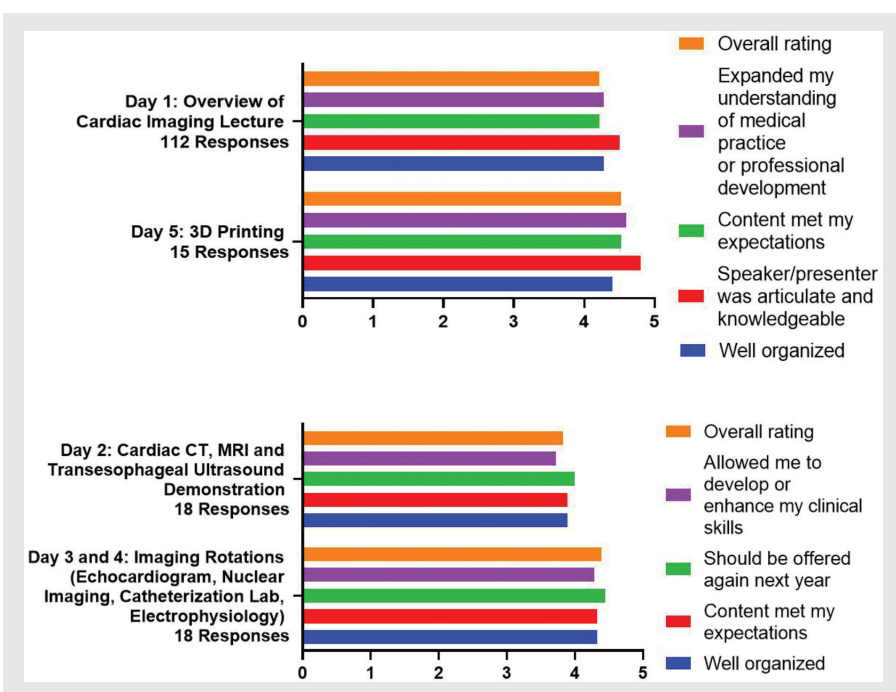

Figure 3. Student responses to a TTUHSC administered assessment of all events taking place over the elective week. The text of each question is indicated in the legend to the right of each graph; each individual bar represents the average response of students to the corresponding question listed in the legend. 
- Day 1: Overview of Cardiac Imaging LectureOverall rating of $4.22 / 5$. All ratings for this day stayed within the 4.2 to 4.5 range. The most appreciated factor was speaker articulation and knowledge.

- Day 2: Cardiac CT, MRI, and Transesophageal Ultrasound-Overall rating of $3.83 / 5$. However, it still received $4 / 5$ on the questions of whether this session should be offered again next year.

- Days 3 and 4: Imaging Rotations (Catheterization Lab, Electrophysiology, Echocardiogram, Nuclear Imaging)-Overall rating of 4.39/5. The ratings for this day stayed between 4.0 and 4.5 on the 5 point Likert scale evaluating favorability, indicating consistent and high levels of satisfaction across varied metrics.

- Day 5: 3D Printing-Overall rating of 4.53/5. This session was generally the one with the most favorable responses. Most metrics for this day were graded over 4.5.

Responses from the TTUHSC administered assessment suggest student satisfaction with the events offered. Averages and number of respondents were the only values made available to the authors of this paper.

\section{Discussion}

Livingston et al. initially introduced Cardiac Imaging and Innovation Week as part of a larger elective experience focused on introducing first- and secondyear medical students to new technology. ${ }^{5}$ Their work found the experience strengthened student knowledge of medical technology, and the experience in cardiology was rated as second most valuable introduction to the standard curriculum. Our work focused solely on the cardiology aspect of the elective and found improved student perceptions and knowledge of cardiology in line with the findings of Livingston et al. regarding the value of the additional experience.

In general, students rarely get chances to explore all the varied fields medicine has to offer during the traditional medical school curriculum. Extracurricular electives such as this one give students a concrete experience to guide their thought processes while deciding which field to pursue. Aid in navigating choice of career allows future leaders to find their niche early and pursue it. Our surveys conclude that such exercises help us expand our knowledge, even in the cases in which students do not choose the field they explore.

$P$ values less than 0.05 were found for all selfassessment metrics but question 2, "I am considering a career in cardiology." This is consistent with the findings of Agarwal et al., whose meta-analysis of preclinical specialty specific electives showed that while students self-reported increased knowledge or interest, significant increases in residency matching were found only in primary care electives. ${ }^{3}$

The greatest increase in self-assessment was seen for question 4: "Knowledge of electrophysiology, nuclear medicine, ultrasound, and catheterization lab." The relevant sessions for this question were the rotations done on the hospital floor over days 3 and 4 . These sessions featured the most time spent in the hospital and the smallest groups.

There were some limitations in the study, which include the small sample size $(n=8)$ of our selfadministered pre- and post-survey, which suggests that conclusions should be viewed with caution. Furthermore, the anonymous nature of the survey tool implies no guarantee that the respondents of the post-survey are identical to those of the pre-survey. There is also the issue of self-selection, since it is possible only the most motivated students attended all events and answered the survey. With that in mind, the results are consistent with the positive selfassessment measures reported in cases of preclinical elective activities.

Overall, our findings reiterate the value of enrichment experiences during the preclinical years, and self-assessment indicates increased student understanding and interest in cardiology and the technology that supports it. 
Article citation: Kusko R, Iskandir M, Haynes A, Williams S, Shurmur S, Ansari MM. The effect of a multimodality cardiac imaging elective on pre-clinical medical students. The Southwest Respiratory and Critical Care Chronicles 2020;8(35):72-76

From: Department of Internal Medicine, Texas Tech University Health Sciences Center, Lubbock, Texas

Submitted: $3 / 31 / 2020$

Accepted: 6/26/2020

Reviewer: Steven Urban MD

Conflicts of interest: none

This work is licensed under a Creative Commons Attribution-ShareAlike 4.0 International License.

\section{REFERENCES}

1. Cooper EM. Innovative midwifery teaching for medical students and residents. J Midwifery Womens Health 2009; 54(4):301-5.

2. Jaroudi SS, Sessions WS, Wang VS, et al. Impact of culinary medicine elective on medical students' culinary knowledge and skills. Proc (Bayl Univ Med Cent) 2018;31(4):439-442.

3. Agarwal A, Wong S, Sarfaty S, et al. Elective courses for medical students during the preclinical curriculum: a systematic review and evaluation. Med Educ Online 2015;20:26615.

4. So S, Patel RM, Orebaugh SL. Ultrasound imaging in medical student education: Impact on learning anatomy and physical diagnosis. Anat Sci Educ 2017;10(2):176-189.

5. Livingston M, Lilley J, Schimelpfenig M, et al. Preparing undergraduate medical students for future practicedevelopment of a future of medicine elective. Am Medical Student Research J 2019;6(1). 